\title{
OPTIMALISASI PENGGUNAAN MEDIA PEMBELAJARAN INTERAKTIF DENGAN MICROSOFT POWER POINT PADA GURU-GURU SEKOLAH DASAR
}

\section{OPTIMIZATION OF INTERACTIVE LEARNING MEDIA USING MICROSOFT POWER POINT ON PRIMARY TEACHER}

\author{
${ }^{1)}$ Jenny Indrastoeti S Poerwanti, ${ }^{2)}$ Hasan Mahfud \\ ${ }^{1,2)}$ Program Studi PGSD FKIP UNS \\ Jl. Slamet Riyadi No. 449 Surakarta \\ Email: jenny_isp@staff.uns.ac.id
}

\begin{abstract}
ABSTRAK
Permasalahan yang dihadapi oleh mitra adalah kurangnya kemampuan para guru dalam menggunakan program power point Microsoft sebagai media pembelajaran di kelas. Oleh Program ini bertujuan untuk memotivasi guru sekolah dasar agar memiliki keinginan untuk menggunakan program Microsoft Power point, meningkatkan kemampuan guru sekolah dasar dalam penggunaan teknologi berbasis media dan meningkatkan kreativitas para guru dalam memproduksi model media interaktif yang menggunakan program Power point. Metode yang digunakan adalah ceramah, tanya jawab, praktek langsung/simulasi dengan pendampingan. Kelompok sasaran adalah guru-guru sekolah dasar di Kecamatan Laweyan yang berjumlah 70 guru. Hasil dari pelatihan ini adalah,meningkatnya kemampuan para guru dalam menggunakan Microsoft power point untuk digunakan sebagai media pembelajaran. adapaun persentase kemampuannya adalah sebagai berikut : $80 \%$ guru sudah memiliki kemampuan mengoperasikan program power point seperti, membuat dokumen baru, mempresentasikan dokumen, menutup dan menyimpan dokumen. $78 \%$ guru juga dapat memasukkan gambar dan video pada slide dokumen untuk disajikan serta $73.75 \%$ guru sudah mampu menambah animasi dan suara pada program powerpoint.
\end{abstract}

Kata kunci: Microsoft power point ; Guru sekolah dasar

\section{ABSTRACT}

The problem faced by the partners of elementary school teachers is the lack of ability of teachers in using the Microsoft power point program as a medium of learning in the classroom.The program aims to motivate elementary school teachers to have a desire to use Microsoft Power point programs, improve the ability of primary school teachers in the use of media-based technologies and enhance teachers' creativity in producing interactive media models using Power point programs. The method used is lecture, question and answer, direct practice/simulation with mentoring. Workshop participants were elementary school teachers in Laweyan sub-district with a total of 70 teachers. The result of this training is, the increasing ability of teachers in using Microsoft power point to be used as a medium of learning however, the percentage of skills is as follows, $80 \%$ of teachers already have the ability to operate power point programs such as, creating new documents, presenting documents, closing and storing documents. $78 \%$ of teachers can also include pictures and videos on document slides for 
Jenny Indrastoeti SP \& Hasan Mahfud

Optimalisasi Penggunaan Media Pembelajaran Interaktif Dengan Microsoft Power

Point Pada Guru-Guru Sekolah Dasar

presentation and $73.75 \%$ of teachers are able to add animation and sound to the power point program.

Keywords: Workshop, Microsoft power point, primary school teacher.

Submitted : 20 Januari 2018 Revision: 20 Agustus 2018 Accepted : 23 Agustus 2018

\section{PENDAHULUAN}

Di era globalisasi sekarang ini perkembangan teknologi dapat memotivasi guru dalam mengajar, menyampaikan materi pembelajaran secara interaktif. Sebagai guru di sekolah dasar, dibutuhkan kreatifitas dalam menggunakan teknologi yang digunakan sebagai media pembelajaran interaktif. Dalam upaya memperbaiki proses pembelajaran agar efektif dan fungsional, maka media interaktif pembelajaran sangat penting untuk dimanfaatkan. Pemakaian media dalam proses pembelajaran dimaksudkan untuk mempertinggi daya cerna siswa terhadap informasi atau materi pembelajaran yang diberikan.

Dengan berkembangnya teknologi informatika yang sangat cepat, ada beberapa pilihan media pembelajaran yang dipergunakan. Computer/laptop dapat juga menjadi media pembelajaran, komputer/laptop dapat juga sebagai alat komunikasi melalui internet yang berfungsi untuk mencari informasi di dunia. Di dalam program computer/laptop ada salah satu program Microsoft Power Point yang dapat juga digunakan guru sebagai media pembelajaran yang interaktif dalam menyampaikan materi pembelajaran.

Materi pembelajaran dalam IPA di sekolah dasar sering disebut sebagai materi pembelajaran yang cukup sulit, karena banyak konsep-konsep yang abstrak sulit dimengerti oleh siswa. Hal ini karena selama pembelajaran guru kurang menekankan pada kegiatan praktek/eksperimen serta penyampaian yang monoton, tidak ada pembaharuan khususnya dalam penyampaian materi. Sedangkan pembelajarn IPS merupakan pembelajaran yang mengandung banyak fakta-fakta dengan konsep-konsep yang sulit dimengerti siswa, sehingga dibutuhkan suatu strategi yang inovatif dalam penyampaian materi agar lebih interaktif dan kreatif.

Guru yang kreatif tentunya dapat menguasai materi yang disampaikan, dengan strategi penyampaian serta keterampilan menggunakan berbagai macam media pembelajaran yang baik, salah satunya adalah penggunaan teknologi informatika.. Walaupun masih ada juga guru yang masih menggunakan buku pelajaran sebagai satu-satunya media pembelajaran. Jika system pengajaran yang digunakan masih bersifat konvensional dikhawatirkan peserta didik sulit berkembang dalam mengikuti perkembangan teknologi.

Ada berbagai macam cara dilakukan oleh guru untuk memenuhi kebutuhan belajar siswa, diantaranya adalah dengan meningkatkan sarana dan prasarana pendidikan. Untuk mengikuti perkembangan zaman dan juga tuntutan tujuan pembelajaran, guru dituntut kreatif dalam meningkatkan sarana proses pembelajaran, salah satunya adalah penggunaan Microsoft powerpoint dalam pembelajaran. Menurut Muhroghibi yang dikutip Mulyawan (2013) dalam pembelajaran, media program Microsoft PowerPoint memiliki kelebihan diantaranya tenaga pendidik tidak perlu banyak menerangkan bahan ajar yang sedang disajikan. 
Jenny Indrastoeti SP \& Hasan Mahfud

Optimalisasi Penggunaan Media Pembelajaran Interaktif Dengan Microsoft Power

Point Pada Guru-Guru Sekolah Dasar

Microsoft Power Point merupakan salah satu program berbasis multi media yang dirancang khusus untuk menyampaikan presentasi. Microsoft Power Point digunakan sebagai media komunikasi yang menarik sehingga peserta didik merasa tidak bosan akan suasana belajar karena pendidik selalu memberikan suasana pembelajaran dengan media pembelajaran yang terus berbeda-beda. Mengoptimalkan Microsoft Power Point sebagai media belajar berarti memanfaatkan secara maksimal segala fitur yang tersedia dalam Microsoft Power Point untuk menunjang kegiatan belajar mengajar .

Ada banyak pilihan media pembelajaran yang dapat digunakan di kelas, khususnya dalam pembelajaran di sekolah dasar namun Power point adalah salah satu pilihan yang paling efektif. Penyajiannya yang menarik adalah salah satu alasan kenapa Power point dikatakan sebagai salah satu media pembelajaran yang efektif, karena ada permainan warna, huruf dan animasi, baik animasi teks maupun animasi gambar atau foto. Hal ini akan lebih merangsang anak untuk mengetahui lebih jauh informasi tentang bahan ajar yang disajikan oleh pendidik. Pesan informasi secara visual lebih mudah dipahami peserta didik dalam menyerap materi pembelajaran. Tenaga pendidik tidak perlu banyak menerangkan bahan ajar yang sedang disajikan, dapat diperbanyak sesuai kebutuhan dan dipakai secara berulang-ulang, disimpan dalam bentuk data optik atau magnetik. (CD / Flashdisk), sehingga praktis.

Hasil penelitian Muharoma, \& Wulandari (2014) menyatakan bahwa pembelajaran dengan menggunakan media powerpoint dapat meningkatkan kualitas pembelajaran. Berdasarkan hasil penelitian tersebut dan kemudahan-kemudahan yang terdapat dalam media pembelajaran, pendidik maupun peserta didik dapat menggunakannya demi tercapainya keberhasilan dalam pembelajaran sesuai dengan bidangnya masing-masing. Dengan kata lain media pembelajaran yang digunakan secara optimal akan menimbulkan efek positif bagi peserta didik untuk belajar lebih giat lagi dan dapat meningkatkan motivasi belajarnya (Mahsun, 2012).

Berdasarkan observasi yang dilakukan di sekolah dasar di Kecamatan Laweyan, permasalahan yang dialami oleh guru-guru adalah, guru kurang maksimal memanfaatkan program Microsoft power point sebagai media dalam menyampaikan materi pembelajaran. Hanya ada satu dua guru yang pernah menggunakan namun belum memanfaatkan secara optimal fitur-fitur atau menu yang tersedia dalam program tersebut mis penggunaan gambar yang bergerak, memasukkan animasi, dan bahkan film. Hal ini tentu, membuat suasana belajar kurang interaktif dan cenderung membosankan karena kurang memotivasi peserta didik dalam menerima pembelajara. Alasan yang disampaikan oleh guru adalah karena mereka belum menguasai fitur-fitur yang ada pada program Microsoft power point.

Dalam menjawab persoalan yang telah diuraikan di atas, dibutuhkan pelatihan dan pendampingan pemanfaatan program Microsoft power point bagi guru-guru sekolah dasar. Hal ini sebagai upaya membekali guru memanfaatkan teknologi computer beserta software program yang tersedia pada perangkat computer.

Berdasarkan permasalahan yang dialami mitra, maka kegiatan pelatihan dan pendampingan ini bertujuan untuk memberikan pelatihan kepada guru-guru sekolah dasar di Kecamatan Laweyan Surakarta tentang penggunaan program Microsoft power point sebagai media pembelajaran di sekolah

\section{METODE KEGIATAN}


Jenny Indrastoeti SP \& Hasan Mahfud

Optimalisasi Penggunaan Media Pembelajaran Interaktif Dengan Microsoft Power

Point Pada Guru-Guru Sekolah Dasar

Pemecahan masalah yang diuraikan di atas dilakukan melalui pelatihan dan pendampingan penggunaan program Microsoft Power point pada guru-guru SD, serta diharapkan dapat mengatasi permasalahan yang dihadapi guru dalam memaksimalkan penggunaan program tersebut. Kerangka pemecahan masalah di atas dapat diuraikan sebagai berikut:

1. Menetapkan jumlah peserta pelatihan yaitu guru-guru SD di Kecamatan Laweyan masing-masing gugus diundang 5 guru

2. Kegiatan dilaksanakan di ruang pertemuan yang dihadiri oleh 70 peserta guru dari 5 sekolah dasar di kecamatan Laweyan Surakarta.

3. Ceramah penyampaian materi pelatihan tentang konsep/teori Microsoft PowerPoint

4. Berlatih mempraktekkan penggunaan program Microsoft PowerPoint sebagai media pembelajaran.

5. Melakukan tindak lanjut dengan pendampingan yang dilakukan secara kelompok.

Pendekatan dilakukan bersama-sama dengan mitra merencanakan metode, teknik dan waktu yang tepat dalam melaksanakan pelatihan.

Berikut ini adalah tahapan pelatihan yang dilakukan:

Tahap Persiapan: tahap persiapan yang dilakukan meliputi survey, pemantapan dan penentuan lokasi sasaran.

Tahap pelaksanaan Pelatihan: Dalam tahap ini dilakukan penjelasan tentang Microsoft PowerPoint dan dilanjutkan dengan praktek bersama-sama menggunakan program tersebut sebagai media pembelajaran. Untuk melaksanakan kegiatan di atas digunakan metode ceramah, tanya jawab dan praktek langsung/simulasi menyampaikan materi pelatihan tentang konsep-konsep yang harus dipahami dalam menu-menu program Microsoft PowerPoint.

Metode tanya jawab digunakan untuk mengetahui sejauh mana peserta telah ikut berpartisipasi dan memahami tentang materi yang disampaikan.

Metode demonstrasi, dipilih untuk menunjukkan suatu proses kerja yaitu tahap-tahap pembuatan dan pemanfaatan program Microsoft power point.. Demonstrasi dilakukan oleh instruktur di hadapan peserta yang secara berkelompok mengoperasikan laptop, sehingga peserta dapat mengamati secara langsung metode dan teknik penulisan pada silde powerpoint serta penggunaan program-programnya secara maksimal.

Metode Simulasi : Dalam metode simulasi ini diberi kesempatan kepada peserta didik, untuk mempraktekkan materi pelatihan yang diterima. Hal ini diharapkan peserta pelatihan benar-benar menguasai materi pelatihan. Melalui pemberian tugas kepada peserta.

Adapun langkah-langkah kegiatan yang dilakukan adalah pendampingan secara intensif dengan tahapan sebagai berikut:

1. Ceramah tentang pengenalan konsepkonsep program power point.

2. Ceramah tentang cara-cara membuat isi slide power point. Pada tampilan gambar di bawah sudah dapat memulai menuliskan judul dan mengisi isi slide kemudian disimpan.

Metode Ceramah dan Tanya Jawab digunakan dalam pelatihan ini untuk 
Jenny Indrastoeti SP \& Hasan Mahfud

Optimalisasi Penggunaan Media Pembelajaran Interaktif Dengan Microsoft Power Point Pada Guru-Guru Sekolah Dasar

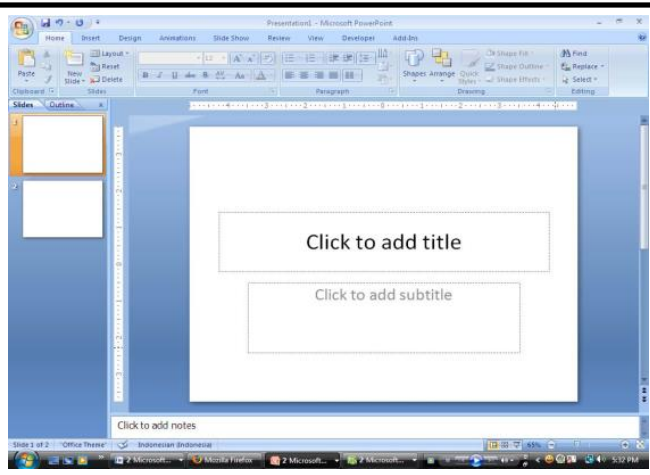

3. Demonstrasi tentang langkah-langkah membuat dan mengembangkan isi slide power point.

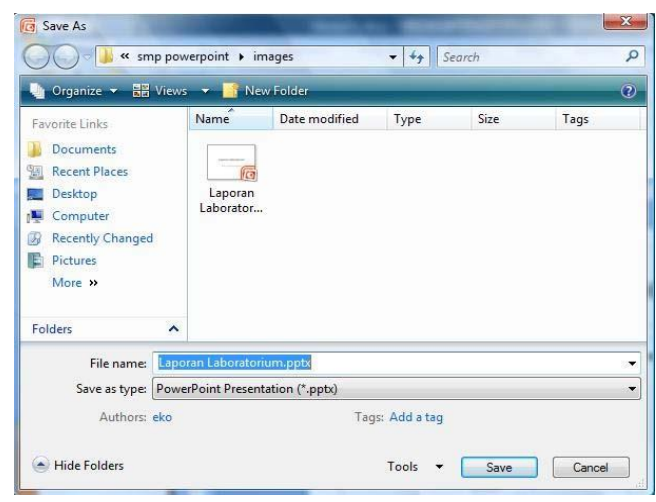

4. Latihan secara berkelompok membuat dan mengembangan isi slide power point, dengan mengisi animasi dan suara, dilanjutkan dengan presentasi.

5. Menambah animasi dan sound, aktifkan tombol teks "tombol office" klik tab menu animation >custom animation. Pada kotak dialog yang muncul, klik icon menu add effect $>$ enterence $>$ box Klik kembali icon menu add effect > motion paths $>$ down

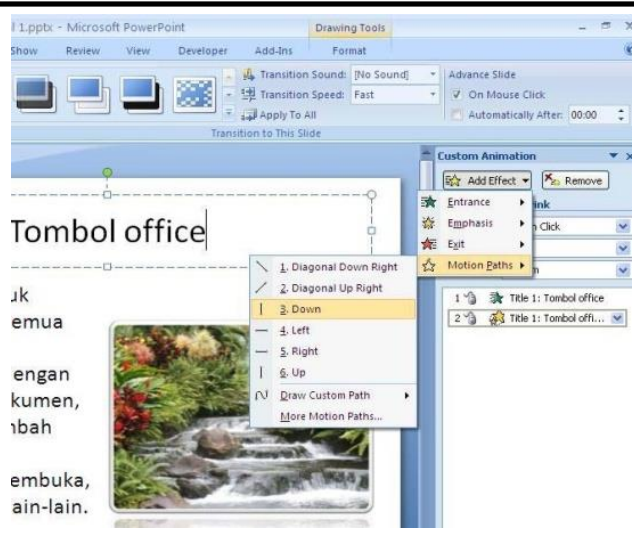

Untuk keluar klik kembali add effect > exit> fly out

6. Evaluasi hasil kegiatan yang telah dilaksanakan.

\section{HASIL DAN PEMBAHASAN}

Hasil yang diperoleh dari kegiatan ini adalah, sebagian besar peserta antusias mendengarkan dan bersemangat untuk melaksanakan praktik sekalipun laptop yang digunakan terbatas. Hal ini terlihat dari banyaknya peserta yang hadir dalam kegiatan pelatihan tersebut serta banyaknya peserta yang bertanya dan berdiskusi dengan pemateri. Isi materi yang disampaikan dalam pelatihan diantaranya tentang membuat dokumen, membuka dan menyimpan, memasukkan gambar pada dokumen sampai pada mengisi animasi dengan sound (suara). Penyampain materi, menggunakan media powerpoint diikuti dengan peserta yang juga berlatih menggunakannya, sehingga dapat mengalami sendiri cara menggunakan media power point. Sejalan dengan hal ini Sanjaya (2009) menyatakan melalui kerucut pengalamannya bahwa pengalaman yang diperoleh peserta dapat melalui proses perbuatan atau mengalami sendiri apa yang dipelajari, proses mengamati dan mendengarkan melalui media. 
Jenny Indrastoeti SP \& Hasan Mahfud

Optimalisasi Penggunaan Media Pembelajaran Interaktif Dengan Microsoft Power Point Pada Guru-Guru Sekolah Dasar

Dari hasil angket yang diberikan pada guru-guru hanya $20 \%$ guru yang pernah mengikuti pelatihan pemanfaatan program komputer, sehingga masih banyak guru-guru yang belum pernah menggunakan program microsoft power point. Hal ini membuat antusiasme guruguru sangat baik, walaupun waktu yang disediakan terbatas. Antusiasme peserta karena di dalam microsoft power point terdapat banyak fitur-fitur yang menarik. Di dalam microsoft powerpoint terdapat menumenu yang memungkinkan pengguna membuat dan mengembangkan media pembelajaran lebih menarik, lebih interaktif, dan lebih menyenangkan (Muhson, Baroroh \& Mustofa, 2012).

Ketercapaian tujuan pelatihan, pada umumnya sudah baik, karena $80 \%$ guru-guru peserta latihan sudah memiliki kemampuan mengoperasikan Microsoft power point, seperti membuat dokumen baru, membuka, sampai pada menyimpan dokumen. $78 \%$ guru juga dapat memasukkan gambar dan video pada slide dokumen untuk disajikan serta $73.75 \%$ guru sudah mampu menambah animasi dan suara pada program powerpoint.

Semua peserta antusias mengikuti pelatihan tersebut namun karena keterbatasan waktu sehingga belum semua materi yang disampaikan dapat dipraktekkan secara kelompok. Untuk mengatasi hal ini, guru-guru peserta latihan diberi tugas membuat dokumen dengan Microsoft power point agar ketika monitoring diadakan, para guru dapat mempraktekkannya. Hasil pelaksanaan pelatihan ini dapat digambarkan dalam tabel di bawah berikut ini:
Tabel 1. Hasil Kemampuan Peserta Latihan Program Microsoft Power Point

\begin{tabular}{|c|c|c|}
\hline No. & Aktivitas & Persentase \\
\hline 1. & $\begin{array}{l}\text { Pengenalan Microsoft } \\
\text { Power Point } \\
\text { a. Menjalankan } \\
\text { b. Mengaktifkan menu } \\
\text { c. Menutup program }\end{array}$ & $\begin{array}{l}100 \% \\
100 \% \\
100 \%\end{array}$ \\
\hline 2. & $\begin{array}{l}\text { Menjalankan Microsoft } \\
\text { Power Point } \\
\text { a. Membuat dokumen } \\
\text { baru } \\
\text { b. Mempresentasikan } \\
\text { dokumen } \\
\text { c. Menutup dokumen } \\
\text { d. Menyimpan } \\
\text { presentasi }\end{array}$ & $\begin{array}{l}80 \% \\
70 \% \\
90 \% \\
80 \%\end{array}$ \\
\hline 3. & $\begin{array}{l}\text { Menambah Gambar. Clip } \\
\text { Art dan Shape } \\
\text { a. Menambah gambar } \\
\text { dalam slide } \\
\text { presentasi } \\
\text { b. Menambah Clip art } \\
\text { dan shape } \\
\text { c. Menambahkan } \\
\text { Objek Shape dalam } \\
\text { dokumen presentasi }\end{array}$ & $\begin{array}{l}75 \% \\
80 \%\end{array}$ \\
\hline 4. & $\begin{array}{l}\text { Menambah } \\
\text { Snimasi, } \\
\text { Sound dan Movies } \\
\text { a. Mengatur animasi } \\
\text { dalam presentasi } \\
\text { berjalan secara } \\
\text { otomatis } \\
\text { b. Mengatur efek } \\
\text { perpindahan slide } \\
\text { c. Menambah File } \\
\text { Video ke alam slide } \\
\text { d. Mengatur suara } \\
\end{array}$ & $75 \%$ \\
\hline
\end{tabular}

Dari tabel 1 di atas dapat digambarkan bahwa pada aspek aktivitas pengenalan terhadap program microsoft power point semua peserta sudah dapat mengenal dengan sangat baik. Pada aktivitas menjalankan program dengan memulai membuat dokumen dan mempresentasi sampai pada menutup dan menyimpan dokumen presentasi sebagian 
Jenny Indrastoeti SP \& Hasan Mahfud

Optimalisasi Penggunaan Media Pembelajaran Interaktif Dengan Microsoft Power

Point Pada Guru-Guru Sekolah Dasar

besar peserta sudah dapat melaksanakan. Pada aktivitas menambah gambar, video dan menjalankan secara otomatis juga sudah cukup baik walaupun sebagian kecil peserta latihan masih belum mampu.

Dampak secara keseluruhan dari hasil kegiatan pelatihan ini sudah dapat dikatakan berhasil dan memberi manfaat bagi para guruguru SD dalam menambah pengetahuan dan teknologi. Hal ini juga berkontribusi pada keaktifan dan keefektifan proses pembelajaran di sekolah dasar.

\section{SIMPULAN}

Hasil pelatihan optimalisasi penggunan microsof power point sebagai media interaktif dalam pembelajaran di sekolah dasar bagi guru adalah (1) Guru memperoleh pengetahuan tentang penngunaan Microsoft power point yang dapat digunakan sebagai media interaktif. (2) Kegiatan ini dapat memotivasi guru-guru SD untuk menggunakan programprogram dalam komputer sebagai media pembelajaran (3) Guru dapat mengembangkan kreativitasnya dalam berkarya meringkas materi pembelajaran dengan menggunakan program microsoft powerpoint dibutuhkan untuk menjalankan tugas kependampingan.

\section{DAFTAR PUSTAKA}

Mahsun. (2012). Metode Penelitian Bahasa: Tahapan Strategi, Metode, dan Tekniknya. Jakarta: Rajawali Pers.

Muharoma, Y.P., \& Wulandari D., (2014). Penerapan Model Problem Based Learning dengan Media Powerpoint untuk Meningkatkan Kualitas Pembelajaran IPA. Joyful Learning Journal. 3, (2).
Muhson, A., K. Baroroh dan Mustofa. (2012). Pembuatan media pembelajaran interaktif dengan microsoft power point. (Online). (http://ejournal.unesa.ac.id/inde x.php/bioedu. Diakses tgl 31 Juli 2018.

Mulyawan, D. (2013). Pengaruh Penggunaan Microsoft Powerpoint. (Online). (http://danimulyawan.38.blogspot.c om/2013/01/jurnalpengaruhpenggunaan-microsoft.html. Diakses 21 Juli 2018

Sanjaya, W. (2009). Strategi Pembelajaran Berorientasi Standar Proses Pendidikan. Jakarta: Kencana 